\title{
A FUZZY MULTIPLE CRITERIA DECISION MAKING MODEL FOR AIRLINE COMPETITIVENESS EVALUATION
}

\author{
Hsuan-Shih Lee \\ Professor \\ Department of Shipping and Transportation \\ Management, National Taiwan Ocean \\ University, Keelung 202, Taiwan, R.O.C. \\ Fax: 886224631903 \\ E-mail: hslee@axp1.stm.ntou.edu.tw
}

\author{
Ching-Wu Chu \\ Professor \\ Department of Shipping and Transportation \\ Management, National Taiwan Ocean \\ University, Keelung 202, Taiwan, R.O.C. \\ Fax: 886224631903 \\ E-mail: cwchu@mail.ntou.edu.tw \\ Ming-Tao Chou \\ Assistant Professor \\ Department of Aviation and Maritime \\ Management, Chang Jung Christian \\ University, Tainan 711, Taiwan, R.O.C. \\ Fax: 886627855056 \\ E-mail:mtchou@mail.cju.edu.tw
}

\begin{abstract}
This article presents a new fuzzy multiple criteria decision making model for the evaluation of airline competitiveness over a period. The evaluation problem is formulated as a fuzzy multiple criteria decision making problem and solved by our strength-weakness based approach. For finding out the strength and weakness of an airline over another airline, we present a preference function based on the extended fuzzy preference relation. The strength and weakness matrices are then calculated based on the preference function. We propose a method to aggregate the weights of criteria, strength matrix and weakness matrix into the strength indices and the weakness indices of airlines, by which each airline can identify its own strength and weakness. The strength and weakness indices can be further integrated into an overall performance indices, by which airlines can identify their competitiveness ranking.
\end{abstract}

Key Words: fuzzy multiple criteria decision making, airline competitiveness

\section{INTRODUCTION}

Airline competitiveness can be measure by a range of efficiency and effectiveness performance measures across a number of distinct dimensions that can reflect the capabilities and offerings of airlines in serving their customers. The performance evaluation of airlines can be measured in terms of some key competitiveness measures, such as cost (Oum and Yu, 1998), operational performance (Bureau of Industry Economics, (1994) and Schefczyk (1993)), cost and productivity (Encaoua (1991) and Windle (1991)), price and productivity (Good and Rhodes (1991)), price and service quality (Bureau of Transportation and Communications Economics, (1993)), productivity and efficiency (Good et al. (1993), Good et al. (1995), Oum and Yu (1995), Windle and Dresner (1995)), profitability (Bureau of Transportation and Communications Economics, (1993), Oum and Yu (1995), safety (Janic 
(2000)), service quality (Chang and Yeh (2002), Young et al. (1994)), and service quality and productivity (Truitt and Haynes (1994)). However, these single measures alone do not reflect the overall airline competitiveness. In this paper, we assume the key performance measures used are cost $\left(\mathrm{C}_{1}\right)$, productivity $\left(\mathrm{C}_{2}\right)$, service quality $\left(\mathrm{C}_{3}\right)$, price $\left(\mathrm{C}_{4}\right)$, and management $\left(\mathrm{C}_{5}\right)$ (Chang and Yeh (2001)).

An airline competitiveness evaluation problem can be formulated as a multiple criteria decision making problem in which the alternatives are the airlines to be evaluated and the criteria are the performance measures of airlines under consideration. Assume there $m$ airlines to be evaluated against $n$ measures. The problem can be expressed in matrix format as follows:

$$
\begin{gathered}
C_{1} \\
C_{1} \\
A_{1} \\
A_{2} \\
\vdots \\
A_{m}
\end{gathered}\left[\begin{array}{cccc}
x_{11} & x_{12} & \cdots & x_{1 n} \\
x_{21} & x_{22} & \cdots & x_{2 n} \\
\vdots & \vdots & \vdots & \vdots \\
x_{m 1} & x_{m 2} & \cdots & x_{m n}
\end{array}\right]
$$

and $W=\left[\begin{array}{llll}w_{1} & w_{2} & \cdots & w_{n}\end{array}\right]$

where $A_{1}, A_{2}, \ldots, A_{m}$ are the airlines to be evaluated, $C_{1}, C_{2}, \ldots, C_{n}$ are the performance measure against which the performance of airlines are measured, $x_{i j}$ is the performance rating of $i$-th airline against $j$-th criterion, and $w_{j}$ is the weight of $j$-th criterion.

In traditional MCDM, performance rating and weights are measured in crisp numbers (Dyer et al. (1992), Hwang and Yoon (1981) and Teghem et al. (1989)). To evaluate competitiveness of airlines in a specific year, traditional MCDM methods may suffice, since all performance ratings are crisp. However, if we want to evaluate the competitiveness of airlines over a period, say 5 years, traditional MCDM methods may be inadequate. We can not represent the performance of an airline under a specific measure by a crisp number, since the performance may vary within a range in 5 years. One way to represent a varying performance over a period is to represent the performance by a fuzzy number. Therefore, fuzzy multiple criteria decision making (FMCDM) is suitable for airline performance evaluation over a period. A FMCDM for $m$ airlines and $n$ criteria can be modeled as follows:

$$
D=\left[\begin{array}{cccc}
\tilde{A}_{11} & \tilde{A}_{12} & \ldots & \tilde{A}_{1 n} \\
\tilde{A}_{21} & \tilde{A}_{22} & \ldots & \tilde{A}_{2 n} \\
\vdots & \vdots & \vdots & \vdots \\
\tilde{A}_{m 1} & \tilde{A}_{m 2} & \cdots & \tilde{A}_{m n}
\end{array}\right]
$$


and

$W=\left[\begin{array}{cccc}\tilde{w}_{1} & \tilde{w}_{2} & \cdots & \tilde{w}_{n}\end{array}\right]$

where $\tilde{A}_{i j}$ is the fuzzy number representing the performance of $i$-th airline under $j$-th

criterion and $\tilde{W}_{j}$ is the fuzzy number representing the weight of $j$ th criterion.

In dealing with fuzzy numbers, ranking fuzzy number is one of the important issues. Many methods for fuzzy ranking have been proposed (Baas and Kwakernaak (1977), Bortolan and Degani (1985), Chang (1981), Chen (1985), Delgado (1988), Dubois and Prade (1983), Dyer et al. (1992), Lee (2001), Nakamura (1986), Teghem et al. (1989) and Yuan (1991)). They can be classified into two categories. The first category is based on defuzzification. Various methods of defuzzification have been proposed. In the first category, fuzzy numbers are defuzzified into crisp numbers or the so-called utilities in some literatures. The ranking are then done based on these crisp numbers. Though it is easy to compute, the main drawback of this type is that defuzzification tends to loss some information and thus is unable to grasp the sense of uncertainty. The other category is based on fuzzy preference relation. The advantage of this type is that uncertainties of fuzzy numbers are kept during ranking process. However, the fuzzy preference relations proposed thus far are too complex to compute. Yuan (1991) has proposed criteria for measuring ranking method. Lee (2001) has proposed a new fuzzy ranking method based on fuzzy preference relation satisfying all criteria proposed by Yuan. In Lee (2002), we extended the definition of fuzzy preference relation and propose an extended fuzzy preference relation which satisfies additivity and is easy to compute.

In this paper, we are going to propose a new FMCDM to evaluate the competitiveness of airlines over a period. To find out the strength and weakness of an airline over another airline, we present a preference function based on the extended fuzzy preference relation proposed in Lee (2002). The strength and weakness matrices are then calculated based on the preference function. We propose a method to aggregate the fuzzy weights of criteria, strength matrix and weakness matrix into the strength indices and the weakness indices of airlines, by which airlines can identify their strength and weakness. The strength and weakness indices can be further integrated into an the overall performance indices, by which airlines can identify their competitiveness ranking.

\section{PRELIMINARIES}


Definition 2.1 The $\alpha$-cut of fuzzy set $A, A^{\alpha}$ is the crisp set $A^{\alpha}=\left\{x \mid \mu_{A}(x) \geq \alpha\right\}$. The support of $A$ is the crisp $\operatorname{Supp}(A)=\left\{x \mid \mu_{A}(x)>0\right\} . A$ is normal iff $\sup _{x \in U} \mu_{A}(x)=1$, where $U$ is the universal set.

Definition 2.2 A fuzzy subset $A$ of a real number $R$ is convex iff $\mu_{A}(\lambda x+(1-\lambda) y) \geq$ $\left(\mu_{A}(x) \wedge \mu_{A}(y)\right), \forall x, y \in R, \forall \lambda \in[0,1]$, where $\wedge$ denotes the minimum operator.

Definition 2.3 $A$ is a fuzzy numbers iff $A$ is a normal and convex fuzzy subset of $R$. Definition 2.4 A triangular fuzzy number $A$ is a fuzzy number with piecewise linear membership function $\mu_{A}(x)$ defined by $\mu_{A}(x)=\left\{\begin{array}{l}\frac{x-a_{1}}{a_{2}-a_{1}}, a_{1} \leq x \leq a_{2}, \\ \frac{a_{3}-x}{a_{3}-a_{2}}, a_{2} \leq x \leq a_{3}, \text { which can denoted as } \\ 0 \text {, otherwise, }\end{array}\right.$ $\operatorname{triplet}\left(a_{1}, a_{2}, a_{3}\right)$.

Definition 2.5 Let $A$ and $B$ be two fuzzy numbers. Let $\circ$ be an operation on real numbers, such as $+,-,^{*}, \wedge, \vee$, etc. By extension principle, the extended operation $\circ$ on fuzzy numbers can be defined by $\mu_{A \circ B}(z)=\sup _{x, y: z=\mathrm{x} \circ \mathrm{y}}\left\{\mu_{A}(x) \wedge \mu_{B}(x)\right\}$.

Definition 2.6 Let $A$ be a fuzzy number. Then $A_{\alpha}^{L}$ and $A_{\alpha}^{U}$ are defined as

$$
A_{\alpha}^{L}=\inf _{\mu_{A}(z) \geq \alpha}(z)
$$

and

$$
A_{\alpha}^{U}=\sup _{\mu_{A}(z) \geq \alpha}(z)
$$

respectively.

Definition 2.7 A fuzzy preference relation $R$ is a fuzzy subset of $R \times R$ with membership function $\mu_{R}(A, B)$ representing the degree of preference of fuzzy number $A$ over fuzzy number $B$.

1. $R$ is reciprocal iff $\mu_{R}(A, B)=1-\mu_{R}(B, A)$ for all fuzzy numbers $A$ and $B$.

2. $R$ is transitive iff $\mu_{R}(A, B) \geq(1 / 2)$ and $\mu_{R}(B, C) \geq(1 / 2) \Rightarrow \mu_{R}(A, C) \geq(1 / 2)$ for all fuzzy numbers $A, B$ and $C$.

3. $R$ is a fuzzy total ordering iff $R$ is both reciprocal and transitive.

If fuzzy numbers are compared both based on fuzzy preference relations, then $A$ is said to be greater than $B$ iff $\mu_{R}(A, B)>(1 / 2)$.

Definition 2.8 An extended fuzzy preference relation $R$ is an extended fuzzy subset of $R \times R$ with membership function $-\infty \leq \mu_{R}(A, B) \leq \infty$ representing the degree of preference of fuzzy number $A$ over fuzzy number $B$.

1. $R$ is reciprocal iff $\mu_{R}(A, B)=-\mu_{R}(B, A)$ for all fuzzy numbers $A$ and $B$. 
2. $R$ is transitive iff $\mu_{R}(A, B) \geq 0$ and $\mu_{R}(B, C) \geq 0 \Rightarrow \mu_{R}(A, C) \geq 0$ for all fuzzy numbers $A, B$ and $C$.

3. $R$ is additive iff $\mu_{R}(A, C)=\mu_{R}(A, B)+\mu_{R}(B, C)$.

4. $R$ is a fuzzy total ordering iff $R$ is both reciprocal, transitive and additive.

If fuzzy numbers are compared based on extended fuzzy preference relations, then $A$ is said to be greater than $B$ iff $\mu_{R}(A, B)>0$.

\section{AN EXTENDED FUZZY PREFERENCE RELATION}

Our extended fuzzy preference relation is defined as follows.

Definition 3.1 For any fuzzy number $A$ and $B$, extended fuzzy preference relation $F(A, B)$ is defined by the membership function $\mu_{F}(A, B)=\int_{0}^{1}\left((A-B)_{\alpha}^{L}+(A-B)_{\alpha}^{U}\right) d \alpha$

Lemma 3.1 $F$ is reciprocal, i.e., $\mu_{F}(B, A)=-\mu_{F}(A, B)$

Proof: since $(A-B)_{\alpha}^{L}+(A-B)_{\alpha}^{U}=A_{\alpha}^{L}-B_{\alpha}^{U}+A_{\alpha}^{U}-B_{\alpha}^{L}=-\left(B_{\alpha}^{L}-A_{\alpha}^{U}+B_{\alpha}^{U}-A_{\alpha}^{L}\right)=-\left((B-A)_{\alpha}^{L}+(B-A)_{\alpha}^{U}\right)(6)$ we have $\mu_{F}(B, A)=-\mu_{F}(A, B)$.

Lemma 3.2 $F$ is additive, ie., $\mu_{F}(A, B)+\mu_{F}(B, C)=\mu_{F}(A, C)$

Proof:

$$
\begin{aligned}
& \mu_{F}(A, B)+\mu_{F}(B, C) \\
& =\int_{0}^{1}\left((A-B)_{\alpha}^{L}+(A-B)_{\alpha}^{U} d \alpha+\int_{0}^{1}\left((B-C)_{\alpha}^{L}+(B-C)_{\alpha}^{U} d \alpha\right.\right. \\
& =\int_{0}^{1} A_{\alpha}^{L}-B_{\alpha}^{U}+A_{\alpha}^{U}-B_{\alpha}^{L}+B_{\alpha}^{L}-C_{\alpha}^{U}+B_{\alpha}^{U}-C_{\alpha}^{L} d \alpha \\
& =\int_{0}^{1}\left((A-C)_{\alpha}^{L}+(A-C)_{\alpha}^{U} d \alpha\right.
\end{aligned}
$$

Lemma 3.3 $F$ is transitive, ie., $\mu_{F}(A, B) \geq 0$ and $\mu_{F}(B, C) \geq 0 \Rightarrow \mu_{F}(A, C) \geq 0$

Proof: By lemma 3.2, we have $\mu_{F}(A, C)=\mu_{F}(A, B)+\mu_{F}(B, C)$. Since $\mu_{F}(A, B) \geq 0, \mu_{F}(B, C) \geq 0$, we have $\mu_{F}(A, C) \geq 0$

Lemma 3.4 Let $A=\left(a_{1}, a_{2}, a_{3}\right)$ and $B=\left(b_{1}, b_{2}, b_{3}\right)$ be two triangular fuzzy numbers. $\mu_{F}(A, B) \geq 0$ iff $a_{1}+2 a_{2}+a_{3}-b_{1}-2 b_{2}-b_{3} \geq 0$

Proof: $\mu_{F}(A, B) \geq 0$ iff

$$
\mu_{F}(A, B)=\int_{0}^{1}(A-B)_{\alpha}^{L}+(A-B)_{\alpha}^{U} d \alpha=\frac{a_{1}+2 a_{2}+a_{3}-b_{1}-2 b_{2}-b}{2} \geq 0
$$

Definition 3.2 Let $\geq$ be a binary relation on fuzzy numbers defined by $A \geq B$ iff $u_{F}(A, B) \geq 0$.

Theorem $3.1 \geq$ is total ordering relation.

According to lemma 3.4, we have following lemma.

Lemma 3.5 Let $A=\left(a_{1}, a_{2}, a_{3}\right)$ and $B=\left(b_{1}, b_{2}, b_{3}\right)$ be two triangular fuzzy numbers. Then 
$A \geq B$ iff $a_{1}+2 a_{2}+a_{3}-b_{1}-2 b_{2}-b_{3} \geq 0$.

Lemma 3.6 Let $A=\left(a_{1}, a_{2}, a_{3}, a_{4}, a_{5}, a_{6}\right)$ be a fuzzy number with parabolic membership $\left(\frac{-a_{2}}{2 a_{1}}+\sqrt{\frac{a_{2}^{2}}{2 a_{1}}+\frac{\left(x-a_{3}\right)}{a_{1}}} \quad a_{3} \leq x \leq a_{1}+a_{2}+a_{3}\right.$,

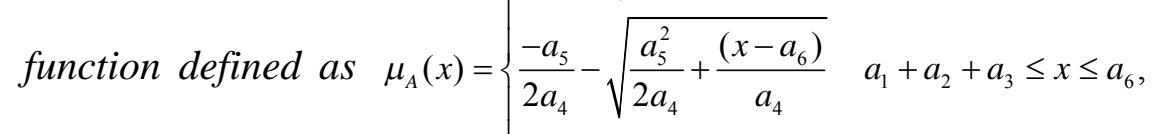

$$
\text { o, } \quad \text { otherwise, }
$$

Let $B=\left(b_{1}, b_{2}, b_{3}, b_{4}, b_{5}, b_{6}\right)$ be another fuzzy number with parabolic membership function. Let

$Q(A, B)=\frac{1}{3}\left(a_{1}+a_{4}-b_{1}-b_{4}\right)+\frac{1}{2}\left(a_{2}+a_{5}-b_{2}-b_{5}\right)+\left(a_{3}+a_{6}-b_{3}-b_{6}\right)$

Then $A \geq B$ iff $Q(A, B) \geq 0$.

In the case of ranking more than two fuzzy numbers, $A_{1}, A_{2}, A_{3}, \ldots, A_{n}$. We may use the relation $F\left(A_{i}, A_{j}\right)$ for pairwise comparison and we need to calculate $(1 / 2) n(n-1) F$ values. To improve computational efficiency, we suggest comparing each fuzzy number. $A_{i}, i=1,2,3, \ldots, n$, with the average fuzzy number $\bar{A}=\sum_{i=1}^{n} A_{i} / n$. Then rank $A_{i}$ according to $\mu_{F}\left(A_{i}, \bar{A}\right)$ which is followed from the additive property of $F$.

Theorem 3.2 It follows that the ranking method based on extended fuzzy preference relation $F$ need $O(n)$ computations of $F$, which is more efficient than any known method.

\section{THE PROPOSED METHOD}

Let $\tilde{A}_{i j}$ be the performance of $i$-th airline under $j$-th criterion. To facilitate our method, we define the preference function of fuzzy number $\tilde{A}_{i j}$ over another number $\tilde{A}_{k j}$ as follows:

$$
P\left(\tilde{A}_{i j}, \tilde{A}_{k j}\right)= \begin{cases}\mu_{F}\left(\tilde{A}_{i j}, \tilde{A}_{k j}\right) & \text { if } \mu_{F}\left(\tilde{A}_{i j}, \tilde{A}_{k j}\right) \geq 0 \\ 0 & \text { otherwise }\end{cases}
$$

Let $J$ be the set of benefit criteria and $J^{\prime}$ be the set of cost criteria where

$$
\begin{aligned}
& J=\{1 \leq j \leq n \text { and } j \text { belongs to benfit criteria }\}, \\
& J^{\prime}=\{1 \leq j \leq n \text { and } j \text { belongs to cost criteria }\}, \text { and } J \cup J^{\prime}=\{1, \ldots, n\} .
\end{aligned}
$$

The strength matrix $S=\left(S_{i j}\right)$ is given by letting 


$$
S_{i j}=\left\{\begin{array}{ll}
\sum_{k \neq i} P\left(\tilde{A}_{i j}, \tilde{A}_{k j}\right) & \text { if } j \in J \\
\sum_{k \neq i} P\left(\tilde{A}_{k j}, \tilde{A}_{i j}\right) & \text { if } j \in J^{\prime}
\end{array} .\right.
$$

Similarly, the weakness matrix $I=\left(I_{i j}\right)$ is given by letting

$$
I_{i j}=\left\{\begin{array}{l}
\sum_{k \neq i} P\left(\tilde{A}_{k j}, \tilde{A}_{i j}\right) \quad \text { if } j \in J \\
\sum_{k \neq i} P\left(\tilde{A}_{i j}, \tilde{A}_{k j}\right) \quad \text { if } j \in J^{\prime}
\end{array} .\right.
$$

The fuzzy weighted strength matrix $\tilde{S}=\left(\tilde{S}_{i}\right)$ can be obtained by

$$
\tilde{S}_{i}=\sum_{j} S_{i j} \tilde{W}_{j}
$$

and the fuzzy weighted weakness matrix $\tilde{I}=\left(\tilde{I}_{i}\right)$ can be obtained by

$$
\tilde{I}_{i}=\sum_{j} I_{i j} \tilde{W}_{j}
$$

where $1 \leq i \leq m$. Now we are ready to present our method for FMCDM.

Step1: Define fuzzy weights $W=\left(\tilde{W}_{j}\right)$ of the performance measures by experts. Assume the evaluation time interval is a period of $T$ years. Let $p_{i j}^{t}$ be the performance value of $i$-th airlines under $j$-th criterion in year $1 \leq t \leq T$. Let triangular fuzzy number $\tilde{A}_{i j}$ be the fuzzy performance of $i$-th airline under $j$-th criterion and be denoted as $\left(a_{i j 1}, a_{i j 2}, a_{i j 3}\right)$. Define fuzzy performance matrix $D=\left(\tilde{A}_{i j}\right)$ of airline over a period by letting

$$
\begin{aligned}
& a_{i j 1}=\min _{1 \leq t \leq T} p_{i j}^{t}, \\
& a_{i j 2}=\frac{\sum_{t=1}^{T} p_{i j}^{t}}{T}, \\
& a_{i j 3}=\max _{1 \leq t \leq T} p_{i j}^{t} .
\end{aligned}
$$

Step 2: Calculate the strength matrix by (17). 
Step 3: Calculate the weakness matrix by (18).

Step 4: Calculate the fuzzy weighted strength indices by (19).

Step 5: Calculate the fuzzy weighted weakness indices by (20).

Step 6: Derive the strength index $S_{i}$ from the fuzzy weighted strength and the weakness indices by

$$
S_{i}=\sum_{k \neq i} P\left(\tilde{S_{i}}, \tilde{S_{k}}\right)+\sum_{k \neq i} P\left(\tilde{I_{k}}, \tilde{I}_{i}\right) .
$$

Step 7: Derive the weakness index $I_{i}$ from the fuzzy weighted strength and the weakness indices by

$$
I_{i}=\sum_{k \neq i} P\left(\tilde{S_{k}}, \tilde{S_{i}}\right)+\sum_{k \neq i} P\left(\tilde{I_{i}}, \tilde{I}_{k}\right)
$$

Step 8: Aggregate the strength and weakness indices into the overall performance indices by

$$
t_{i}=\frac{S_{i}}{S_{i}+I_{i}}
$$

Step 9: Rank airlines by the overall performance index $t_{i}$ for $1 \leq i \leq m$.

\section{NUMERICAL EXAMPLE}

Assume there are three airlines to evaluated under 5 criteria over 5 years. Assume the performance ratings in 5 years are normalized within $[0,10]$ and then converted into fuzzy numbers by (21) (22), and (23) as shown in Table 1. Assume fuzzy weights of criteria are given by experts as shown in Table 1 . The competitiveness ranking of airlines is resolved as follows:

Step 1: The fuzzy performance of airlines and the fuzzy weights of criteria are shown in Table 1.

Step 2: The strength matrix derived by (17) is shown in Table 2.

Step 3: The weakness matrix derived by (18) is shown in Table 3.

Step 4: The fuzzy weighted strength indices of airlines derived by (19) are shown in Table 4.

Step 5: The fuzzy weighted weakness indices of airlines derived by (20 are shown in Table 5 .

Step 6: The strength indices of airlines derived by (24) are shown in Table 6.

Step 7: The weakness indices of airlines derived by (25) are shown in Table 7.

Step 8: The total performance indices aggregated by (26) are shown in Table 8.

Step 9: The rank of airlines by overall performance indices are shown in Table 9.

\section{CONCLUSIONS}

In this paper, we have presented a new FMCDM for airlines performance comparison. With 
our method, two matrices are constructed. Namely, they are the strength matrix and weakness matrix from which the strength and weakness indices are derived. With strength and weakness indices, airlines can identify their strength and weakness under the performance measures taken into consideration. Airlines can identify their competitive positions by the overall performance indices obtained by aggregating the strength and weakness indices.

\section{ACKNOWLEDGMENT}

This research work was supported by the National Science Council of the Republic of China under grant No. NSC93-2416-H-019-004.

\section{REFERENCES}

Baas, S.M. and Kwakernaak, H. (1977) Rating and ranking of multiple-aspect alternatives using fuzzy sets, Automatica, Vol.13, 47-58.

Bortolan, G. and Degani, R. (1985) A review of some methods for ranking fuzzy subsets, Fuzzy Sets and Systems, Vol.15, 1-19.

Bureau of Industry Economics. (1994) Aviation: international performance indicators. Research report 59. Canberra: Australian Government Publishing Service.

Bureau of Transportation and Communications Economics (1993) The progress of aviation reform, Re-search report 81. Canberra: Australian Government Publishing Service.

Chang, W. (1981) Ranking of fuzzy utilites with triangular membership functions, Proc. Internat. Conf. on Policy Analysis and Information Systems, 263-272.

Chang, Y.-H. and Yeh, C.-H. (2001) Evaluating airline competitiveness using multiattribute decision making, Omega, Vol.29, 405-415.

Chang, Y.H. and Yeh, C.H. (2002) A survey analysis of service quality for domestic airlines, European Journal of Operational Research, Vol.139, No.1, 166-177.

Chen, S. (1985) Ranking fuzzy numbers with maximizing set and minimizing set, Fuzzy Sets and Systems, Vol.17, 113-129.

Delgado M., J.L. (1988) Verdegay and M.A. Vila. A procedure for ranking fuzzy numbers using fuzzy relations, Fuzzy Sets and Systems, Vol. 26, 49-62.

Dubois, D. and Prade, H. (1983) Ranking fuzzy numbers in the setting of possibility theory, Inform. Sci., Vol. 30, 183-224.

Dyer J.S., Fishburn, P.C. Steuer, R.E. Wallenius, J. and Zionts, S. (1992) Multiple criteria decision making, Multiattribute utility theory: The next ten years, Management Sci., Vol. 38, No. 5, 645-654.

Encaoua, D. (1991) Liberalizing European airlines: cost and factor productivity evidence, 
International Journal of Industrial Organization, Vol.9, 109-124.

Good, D.H., and Rhodes, E.L. (1991) Productive efficiency, technological change and the competitiveness of U.S. airlines in the Pacific Rim, Journal of the Transportation Research Forum, Vol.31, No.2, 347-358.

Good, D.H., L.H. Roller, and Sickles, R.C. (1995) Airline efficiency differences between Europe and the US: implications for the pace of EC integration and domestic regulation, European Journal of Operational Research, Vol.80, No.1, 508-518.

Good, D.H., M.I. Nadiri, L.H. Roller, and Sickles, R.C. (1993) Efficiency and productivity growth comparisons of European and U.S. airlines: a first look at the data, The Journal of Productivity Analysis, Vol.4, 115-125.

Hwang, C.L., and Yoon, K. (1981) Multiple Attributes Decision Making Methods and Applications. Springer, Berlin Heidelberg,.

Janic, M. (2000) An assessment of risk and safety in civil aviation, Journal of Air Transport Management, Vol.6, 43-50.

Lee H.-S. (2002) An Extended Fuzzy Preference Relation for Comparison of Fuzzy Numbers, The 6h World Multi-Conference on Systemics, Cybernetics and Informatics, July 14-18, , Orlando, USA, XI, 76-79.

Lee, H.-S. (2001) A new fuzzy ranking method based on fuzzy preference relation, 2000 IEEE International Conference on Systems, Man And Cybernetics, 3416-3420.

Matthew, J.L. and Bruce, P.J. (2003) Factors influencing the usage and selection of project management software, IEEE Transactions on Engineering Management, Vol.50, 164-172.

Montazemi, A.R. (1996) An empirical study factors affecting software package selection, Journal of Management Information Systems, Vol. 13, 89-106.

Nakamura, K. (1986) Preference relations on a set of fuzzy utilities as a basis for decision making, Fuzzy Sets and Systems, Vol.20, 147-162.

Oum, T.H. and Yu, C. (1998) Cost competitiveness of major airlines: an international comparison, Transportation Research part A, Vol.32, No.6, 407-422.

Oum, T.H., and Yu, C. (1995) A productivity comparison of the world's major airlines, Journal of Air Transport Management, Vol.2, No.3/4, 181-195.

Schefczyk, M. (1993) Operational performance of airlines: an extension of traditional measurement paradigms, Strategic Management Journal, Vol.14, 301-317.

Teghem, J.J., Delhaye, C. and Kunsch, P.L. (1989) An interactive decision support system (IDSS) for multicriteria decision aid, Math. Comput. Modeling, Vol.12, 1311-1320.

Truitt, L.J. and Haynes, R. (1994) Evaluating service quality and productivity in the regional airline industry, Transportation Journal, Vol.33, No.4, 21-32.

Windle R. and Dresner, M. (1995)A note on productivity comparisons between air carries, 
Logistics and Transportation Review, Vol.31, No.2, 125-134.

Windle, R. (1991) The world's airlines: a cost and productivity comparison, Journal of Transport Economics and Policy, Vol.25, No.1, 31-49.

Yager, R.R. (1981) A procedure for ordering fuzzy subsets of the unit interval, Inform. Sci., Vol.24, 143-161.

Young, C., Lawrence, C. and Lee, M. (1994) Assessing service quality as an effective management tool: the case for the airline industry, Journal of Marketing Theory and Practice, Vol.2, No.2, 76-96.

Yuan, Y. (1991) Criteria for evaluating fuzzy ranking methods, Fuzzy Sets and Systems, Vol.44, 139-157 
Table 1. The fuzzy decision matrix and fuzzy weights

\begin{tabular}{llllll}
\hline & $\mathrm{C}_{1}$ & $\mathrm{C}_{2}$ & $\mathrm{C}_{3}$ & $\mathrm{C}_{4}$ & $\mathrm{C}_{5}$ \\
\hline $\mathrm{A}_{1}$ & $(5.7,7.7,9.3)$ & $(5,7,9)$ & $(5.7,7.7,9)$ & $(8.33,9.67,10)$ & $(3,5,7)$ \\
$\mathrm{A}_{2}$ & $(6.3,8.3,9.7)$ & $(9,10,10)$ & $(8.3,9.7,10)$ & $(9,10,10)$ & $(7,9,10)$ \\
$\mathrm{A}_{3}$ & $(6.3,8,9)$ & $(7,9,10)$ & $(7,9,10)$ & $(7,9,10)$ & $(6.3,8.3,9.7)$ \\
Weight & $(0.7,0.9,1)$ & $(0.9,1,1)$ & $(0.77,0.93,1)$ & $(0.9,1,1)$ & $(0.43,0.63,0.83)$ \\
\hline
\end{tabular}

Table 2. The strength matrix

\begin{tabular}{llllll}
\hline & $\mathrm{C}_{1}$ & $\mathrm{C}_{2}$ & $\mathrm{C}_{3}$ & $\mathrm{C}_{4}$ & $\mathrm{C}_{5}$ \\
\hline $\mathrm{A}_{1}$ & 0 & 0 & 0 & 1.335 & 0 \\
$\mathrm{~A}_{2}$ & 2.25 & 7.5 & 0.645 & 2.665 & 8.7 \\
$\mathrm{~A}_{3}$ & 0.45 & 3.5 & 2.45 & 0 & 5.95 \\
\hline
\end{tabular}

Table 3. The weakness matrix

\begin{tabular}{llllll}
\hline & $\mathrm{C}_{1}$ & $\mathrm{C}_{2}$ & $\mathrm{C}_{3}$ & $\mathrm{C}_{4}$ & $\mathrm{C}_{5}$ \\
\hline $\mathrm{A}_{1}$ & 1.8 & 9 & 7.55 & 0.655 & 13.45 \\
$\mathrm{~A}_{2}$ & 0 & 0 & 0 & 0 & 0 \\
$\mathrm{~A}_{3}$ & 0.9 & 2 & 1.35 & 3.335 & 1.2 \\
\hline
\end{tabular}

Table 4. The fuzzy weighted strength indices of airlines

\begin{tabular}{ll}
\hline & fuzzy weighted strength index \\
\hline $\mathrm{A}_{1}$ & $(1.2015,1.335,1.335)$ \\
$\mathrm{A}_{2}$ & $(14.96115,18.27085,20.281)$ \\
$\mathrm{A}_{3}$ & $(7.91,9.932,11.3385)$ \\
\hline
\end{tabular}

Table 5. The fuzzy weighted weakness indices of airlines

\begin{tabular}{ll}
\hline & fuzzy weighted weakness index \\
\hline $\mathrm{A}_{1}$ & $(21.5555,26.78,30.1785)$ \\
$\mathrm{A}_{2}$ & $(0,0,0)$ \\
$\mathrm{A}_{3}$ & $(6.987,8.1565,8.581)$ \\
\hline
\end{tabular}


Table 6. The strength indices of airlines

strength index

\begin{tabular}{ll}
\hline $\mathrm{A}_{1}$ & 50.7927 \\
$\mathrm{~A}_{2}$ & 210.125 \\
$\mathrm{~A}_{3}$ & 31.881 \\
\hline
\end{tabular}

Table 7. The weakness indices of airlines

\begin{tabular}{ll}
\hline & weakness index \\
\hline $\mathrm{A}_{1}$ & 171.8715 \\
$\mathrm{~A}_{2}$ & 31.881 \\
$\mathrm{~A}_{3}$ & 89.04635 \\
\hline
\end{tabular}

Table 8 . The total performance indices of airlines

total performance index

\begin{tabular}{ll}
\hline $\mathrm{A}_{1}$ & 0.228113 \\
$\mathrm{~A}_{2}$ & 0.868264 \\
$\mathrm{~A}_{3}$ & 0.263638 \\
\hline
\end{tabular}

Table 9. The rank of airlines based on overall performance indices rank

\begin{tabular}{ll}
\hline $\mathrm{A}_{1}$ & 3 \\
$\mathrm{~A}_{2}$ & 1 \\
$\mathrm{~A}_{3}$ & 2 \\
\hline
\end{tabular}

